\title{
IMPLEMENTASI SEKOLAH BERBASIS KEARIFAN LOKAL REYOG PONOROGO DI SDN KALIMALANG
}

\author{
Rizki Mustikasari \\ PG-PAUD, STKIP PGRI Ponorogo \\ E-mail: mustikasaririzki@gmail.com
}

\begin{abstract}
Abstrak
Penelitian ini bertujuan untuk mengetahui implementasi sekolah berbasis kearifan lokal di SDN Kalimalang; mengetahuai pemahaman kepala sekolah, ketua tim pengembang, dan guru tentang pengembangan sekolah berbasis kearifan lokal; mengetahui bentuk kearifan lokal yang dikembangkan; dan strategi pengembangan sekolah berbasis kearifan lokal yang diterapkan di SDN Kalimalang.

Penelitian ini menggunakan metode deskriptif kualitatif dengan teknik pemeriksaan data dengan menggunakan triagulasi teknik dan sumber data.

Hasil penelitian menunjukkan bahwa pemahaman pengertian sekolah berbasis kearifan lokal antara kepala sekolah, ketua tim pengembang, dan guru sama, yaitu kondisi sekolah yang menerapkan kearifan lokal dalam suasana pembelajaran. Kearifan lokal yang diterapkan di SDN Kalimalang adalah seni tari, gamelan Reyog, dan kerajianan Reyog. SDN Kalimalang menggunakan lima strategi dalam pengembangan sekolah berbasis kearifan lokal yaitu membuat team work, menyiapkan fasilitas penunjang, melakukan strategi pelaksanaan, melakukan kerjasama dengan pihak luar, dan menjalin kerjasama dengan masyarakat. Bentuk implementasi sekolah berbasis kearifan lokal di SDN Kalimalang dapat dilihat dari pengintegrasian kearifan lokal dalam pembelajaran maupun dalam kegiatan ekstrakurikuler.
\end{abstract}

Kata Kunci: sekolah reyog, sekolah kearifan lokal, kearifan lokal, kearifan lokal reyog

\section{THE IMPLEMENTATION OF SCHOOL BASED ON LOCAL WISDOM OF REYOG PONOROGO IN SDN KALIMALANG}

\begin{abstract}
This study aims to know the implementation of local wisdom-based school in SDN Kalimalang; knowing the principal's, team leader development's, and the teachers' understanding about developing a local wisdom-based school; knowing the developed form of its local wisdom; and the development strategy of a local wisdom-based school applied in that school.

This study was a qualitative descriptive method with triangulation to check the data trustworthiness.

The results of this study showed that the understanding of the principal, the team leader development team, and the teacher is the same, in the school's condition that applies local wisdom in the learning atmosphere. The local wisdom applied in this school is dance art, gamelan reyog, and reyog performance. This school uses five strategies in developing their local wisdombased school, involving making team work, preparing supporting facilities, doing strategies implementation, collaborating with external parties, and collaborating with the community. The implementation form of local wisdom-based schools in the observed school can be seen from the integration of local wisdom in learning and in extracurricular activities.
\end{abstract}

Keywords: reyog schools, local wisdom schools, local wisdom, local logistic wisdom 


\section{PENDAHULUAN}

Dewasa ini pendidikan formal memegang peranan yang sangat penting dalam membangun sumberdaya manusia. Pendidikan yang berkualitas dapat menciptakan manusia yang aktif bekerja dan kreatif. Lebih jauh lagi melalui pendidikan seseorang dapat mengembangkan pengetahuan, wawasan, nilai, dan karakter bahkan sebagai upaya pewarisan budaya, bahkan untuk menilai kualitas suatu bangsa dapat dilihat dari kualitas pendidikan di Negara tersebut.

Undang-undang no. 20, tahun 2003. Pasal 3 tentang fungsi pendidikan memaparkan bahwa, "pendidikan nasional berfungsi mengembangkan kemampuan dan membentuk watak serta peradaban bangsa yang bermartabat dalam rangka mencerdaskan kehidupan bangsa, bertujuan untuk berkembangnya potensi peserta didik agar menjadi manusia yang beriman dan bertakwa kepada Tuhan yang Maha Esa, berakhlak mulia, sehat, berilmu, cakap, kreatif, mandiri, dan menjadi warga negara yang demokratis serta bertanggung jawab". Berdasarkan hal tersebut, maka pendidikan tidak bisa dilepaskan dari suatu kebudayaan yang terdapat dalam suatu masyarakat. Salah satu upaya yang dilakukan oleh pemerintah untuk meningkatkan mutu pendidikan nasional dan menyelaraskannya dengan budaya yang terdapat dalam masyarakat adalah dengan diterapkannya kurikulum 2013. Menurut Naela Khusna Faela Shufa (2018) dalam artikel jurnalnya mengatakan bahwa esensi dari kurikulum 2013 adalah tidak hanya bertujuan untuk meningkatkan pengetahuan peserta didik saja, tetapi juga membekali peserta didik dengan keterampilan serta karakter luhur sesuai kepribadian bangsa Indonesia. Lebih lanjut Naela menjelaskan bahwa mata pelajaran dalam kurikulum 2013 dirancang terpadu antara mata pelajaran yang satu dengan mata pelajaran yang lain atau yang dikenal dengan tematik.

Bentuk mata pelajaran yang tematik dalam kurikulum 2013 memberikan peluang besar bagi pengembangan pendidikan berbasis kearifan lokal. Hal tersebut sesuai dengan pendapat Agus Effendi (2011) dalam artikel ilmiahnya yang mengatakan bahwa nilai-nilai budaya yang dimiliki oleh masyarakat sangat penting ditransformasikan dalam pendidikan, sehingga diketahui, diterima, dan dapat dihayati oleh peserta didik.

Wagiran (2011) melakukan penelitian mengenai pengembangan model pembelajaran berbasis kearifan lokal. Dalam penelitiannya ditemukan hasil bahwa pendidikan berbasis kearifan sangat perlu diterapkan. Data yang diperoleh menunjukkan bahwa sebagian besar guru $(51,2 \%)$ menyatakan bahwa pendidikan kearifan lokal sangat penting diterapkan, $46,4 \%$ guru menyatakan penting, dan hanya $0,9 \%$ yang menyatakan pendidikan kearifan lokal tidak penting.

Tri Tulis Juliyanti (2017) dalam penelitiannya menunjukkan hasil bahwa dengan kearifan lokal guru bisa mengembangkan materi-materi yang akan disampaikan ke siswa, guru lebih luas untuk berinovasi dalam menyampaikan pembelajaran, serta dalam kearifan lokal juga mengangkat budaya suatu daerah.

Eni Puji Astuti dan Ismadi (2013) dalam artikel ilmiahnya meberikan pengertian bahwa kearifan lokal adalah gagasan-gagasan setempat yang bersifat bijaksana penuh kearifan, bernilai baik, yang tertanam dan diikuti oleh anggota masyarakatnya. Sejalan dengan hal tersebut, Zuhdan K. Prasetyo (2013:5) mengartikan bahwa pendidikan berbasis keunggulan lokal merupakan usaha sadar yang terencana melalui penggalian dan pemanfaatan potensi daerah setempat secara arif dalam upaya mewujudkan suasana belajar dan proses pembelajaran, agar peserta didik aktif mengembangkan potensi dirinya untuk memiliki keahlian, pengetahuan dan sikap dalam upaya ikut serta membangun bangsa dan Negara.

Mujiasih dan Suprihatin (2016: 34) mengartika pendidikan berbasis kearifan lokal adalah pendidikan yang lebih didasarkan kepada pangayaan nilai-nilai kultural (budaya). Berdasarkanpengertianyangtelahdikemukakan oleh para peneliti dan para ahli, dapat diketaui pentingnya implementasi sekolah berbasis 
kearifan lokal. Naela Khusna Faela Shufa (2018) dalam artikel ilmiahnya mengemukakan empat langkah yang harus dilakukan dalam implementasi pendidikan berbasis kearifan lokal, yaitu: (1) mengidentifikasi keadaan dan potensi daerah, (2) menentukan fungsi dan tujuan, (3) Menentuka Kriteria dan Bahan Kajian, (4) menyusun rencana pembelajaran.

Penelitian ini dilakukan di SDN Kalimalang Kec. Sukorejo Kabupaten Ponorogo, degan difokuskan pada:

1. Pemahaman kepala sekolah, ketua tim pengembang, dan guru penanggungjawab ekstrakurikuler tentang sekolah berbasis kearifan lokal.

2. Bentuk kearifan lokal yang diterapkan di SDN Kalimalang.

3. Strategi dalam mengembangkan kearifan lokal di sekolah.

4. Implementasi sekolah berbasis kearifan lokal di SDN Kalimalang.

Berdasarkan fokus penelitian tersebut, maka masalah dalam penelitian ini dapat dirumuskan sebagai beriukut:

1. Bagaimana pemahaman kepala sekolah, ketua tim pengembang, dan guru penanggungjawab ekstrakurikuler tentang sekolah berbasis kearifan lokal?

2. Apasaja bentuk kearifan lokal yang diterapkan di SDN Kalimalang?

3. Apa saja strategi yang digunakan dalam mengembangkan sekolah berbasis kearifan lokal di SDN Kalimalang?

4. Bagaimana implementasi sekolah berbasis kearifan lokal di SDN Kalimalang?

Sesuai dengan rumusan masalah yang telah diutarakan, penelitian ini bertujuan untuk :

1. Mendeskripsikan pemahaman kepala sekolah, ketua tim pengembang, dan guru penanggungjawab ekstrakurikuler tentang sekolah berbasis kearifan lokal.

2. Mengetahui bentuk kearifan lokal yang diterapkan di SDN Kalimalang.

3. Mengetahui strategi yang digunakan dalam mengembangkan sekolah berbasis kearifan lokal.

4. Mengetahui implementasi sekolah berbasis kearifan lokal di SDN Kalimalang.

\section{METODE}

Peneliti mnggunakan metode penelitian kualitatif.Jenispenelitianyangdigunakan dalam adalah penelitian deskriptif. Data penelitian diperoleh melalui observasi langsung terhadap obyek penelitian dan studi dokumentasi dengan data yang dihasilkan berupa data sekunder dan data primer. Data yang telah diperoleh kemudian dianalisis melalui tiga tahap yaitu reduksi data, penyajian data, dan diakhiri dengan penarikan kesimpulan.

\section{HASIL DAN PEMBAHASAN}

1. Pemahaman Kepala Sekolah, Tim Pengembang Sekolah Berbasis Kearifan Lokal, dan Guru tentang Sekolah Berbasis Kearifan Lokal

Data tentang pemahaman kepala sekolah, Tim Pengembang Sekolah kearifan Lokal, dan Guru tentang sekolah berbasis kearifan lokal diperoleh dari hasil wawancara terhadap kepala sekolah SDN Kalimalang, yaitu bapak Sarmin S.Pd, Ketua Tim Pengembang Sekolah kearifan local, bapak Priyadi M.Pd, dan Guru penanggung jawab ekstrakurikuler, yaitu Ibu Crysna Dinaningrum S.Pd.

Kepala sekolah mendefinisikan sekolah berbasis kearifan lokal adalah sekolah yang memadukan anatara kurikulum nasional dengan kearifan lokal. Kearifan lokal yang dimaksud adalah kesenian yang berkembang di wilayah dimana sekolah tersebut berada. Definisi tersebut peneliti dapatkan dari hasil wawancara kepada kepala sekolah pada tanggal 7 november 2018.

Pengertian yang senada diungkapkan oleh ketua tim pengembang sekolah berbasis kearifan lokal. Beliau berkata:

"Sekolah berbasis kearifan lokal itu memadukan antara kurikulum nasional dengan kearifan lokal. Jadi sambil mengenalkan kearifan lokal kepada siswa, guru tetap menyampaikan materi sesuai yang diatur dalam kurikulum nasional".

Menurut guru penanggung jawab ekstrakurikuler, sekolah berbasis kearifan lokal adalah sekolah yang di dalam pendidikan dan pembelajarannya memanfaatkan kearifan 
lokal sebagai media untuk mencapai tujuan pembelajaran.

2. Kearifan Lokal yang Dikembangkan di SDN Kalimalang

Kearifan lokal yang dikembangkan di SDN Kalimalang diperoleh dari wawancara dan observasi pada bulan November 2018. Wawancara dilakukan kepada kepala sekolah, ketua tim pengembangan sekolah berbasis kearifan lokal, dan guru penanggungjawab ekstrakurikuler. Berdasarkan hasil wawancara tersebut, diketahui bahwa kearifan lokal yang dikembangkan di SDN Kalimalang adalah seni tari Reyog, seni gamelan reyog, dan seni kerajinan busana Reyog.

Guru penanggungjawab ekstrakurikuler mengatakan, "karena Ponorogo identik dengan Reyog, dan anak-anak juga sangat besar minatnya terhadap seni Reyog, maka kearifan lokal yang kami pilih adalah segala hal yang berhubungan dengan Reyog. Kebetulan juga wali murid sangat mendukung program kami”.

Lebih rinci ketua tim pengembangan sekolah berbasis kearifan lokal menjelaskan" Kearifan lokal yang dikembangkan di sini (SDN Kalimalang) adalah seni Reyog secara utuh. Kalau di sekolah lain hanya mengajarkan tari saja, kami mengajarkan semuanya. Mulai dari cara me-nabuh gamelan Reyog, cara membuat perhiasan untuk menari Reyog beserta tat arias yang digunakan, dan tentunya cara menarikannya". Pernyataan-pernyataan tersebut diperkuat oleh pernyataan kepala sekolah bahwa SDN Kalimalang unggul dalam bidang seni Reyog. Siswa-siswanya diajarkan menari Reyog, me-nabuh gamelan Reyog, dan kerajinan Reyog.

3. Pengembangan Sekolah Berbasis Kearifan Lokal di SDN Kalimalang.

Berdasarkan hasil wawancara dan observasi yang peneliti lakukan, strategi yang diterapkan dalam pengembangan sekolah berbasis kearifan lokal dapat diuraikan sebagai berikut:

a. Membuat Team Work

Dalam rangka melaksanakan pengembangan sekolah berbasis kearifan lokal, SDN Kalimalang membentuk Tim pengembang sekolah berbasis kearifan lokal yang beranggotakan 4 orang guru dan diketuai oleh Prihadi M.Pd. Tim tersebut bertugas untuk membuat desain kearifan lokal yang akan diterapkan di sekolah, baik jenis kearifan lokal yang dikembangkan maupun cara pengembangannya. Selain itu tim pengembang juga bertugas untuk mengembangkan model penerapan kearifan lokal yang terintegrasi dengan mata pelajaran.

b. Menyediakan Fasilitas Penunjang

Berdasarkan observasi dan wawancara yang dilakukan peneliti, sebagai fasilitas penunjang terlaksananya sekolah berbasis kearifan lokal SDN Kalimalang memiliki seperangkat gamelan Reyog, dua set Topeng dadak merak, empat buah topeng ganongan, sepuluh eblek, dua puluh lembar sampur, satu buah topeng klono sewandana, satu buah pecut, lima buah meja payet, lima set perlengkapan jahit tangan, dan sebuah ruang penyimpanan perlengkapan Reyog. Selain yang sudah disebutkan, sekolah juga menyediakan bahan-bahan habis pakai seperti mote payet, benang, kain, dan lilin malam.

c. Menyiapkan Strategi Pelaksanaan

Berdasarkan penjelasan yang diberikan oleh ketua tim pengembang pada sesi wawancara dengan peneliti, strategi pelaksanaan sekolah berbasis kearifan lokal dilakukan melalui kegiatan ekstrakurikuler dan implementasi dalam proses pembelajaran..

d. Menjalin Kerjasama dengan Pihak Luar Pihak SDN Kalimalang melakukan kerjasama dengan Dapur Seni Probo Wengker dalam bentuk pembinaan ekstrakurikuler seni tari dan gamelan Reyog. Pembinaan ekstra kerajinan Reyog dilakukan atas kerjasama dengan paguyuban pengrajin Reyog Ponorogo. Hal tersebut disampaikan oleh kepala sekolah pada saat sesi wawancara dengan peneliti tanggal 7 November 2018. 
Selain kerjasama dalam bentuk pembinaan, SDN Kalimalang juga bekerjasama dengan pemerintah desa Kalimalang dalam hal penyediaan fasilitas bagi pengembangan sekolah berbasis kearifan lokal. Fasilitas yang dimaksud adalah dua set topeng dadak merak, satu buah kendang batangan, dan lima buah meja payet. Kerjasama tersebut peneliti ketahui dari study dokumentasi dengan temuan berupa surat perjanjian kesepakatan antara pihak sekolah dengan pihak pemerintah desa Kalimalang.

e. Melakukan Kerjasama dengan Masyarakat Dalamrangka mengembangkan sekolah berbasis kearifan lokal, SDN Kalimalang melakukan kerjasama dengan masyarakat, terutama masyarakat yang menjadi wali murid di SDN Kalimalang. Bentuk kerjasamanya berupa memberikan bantuan sarana transportasi saat pementasan di luar sekolah, selain itu warga desa kalimalang yang memiliki keterampilan tari, keterampilan gamelan Reyog, atau keterampilan dalam hal kerajinan Reyog sering menjadi instruktur pendamping dan instruktur pengganti ketika instruktur utama berhalangan hadir.

4. Implementasi Sekolah Berbasis Kearifan Lokal di SDN Kalimalang

a. Kearifan Lokal dalam Mata Pelajaran

Penerapan kearifan lokal di SDN Kalimalang dalam proses pembelajaran dilakukan dengan mengintegrasikan kearifan lokal dalam mata pelajaran. Pengintegrasian kearifan lokal dalam mata pelajaran ini bertujuan untuk mengenalkan kearifan lokal setempat pada peserta didik dan sebagai upaya untuk melestarikan kearifan lokal yang ada di daerah tempat sekolah berada.

Berdasarkan hasil observasi, guru-guru di SDN Kalimalang telah mencantumkan kearifan lokal dalam silabus dan rencana pelaksanaan pembelajaran pada mata pelajaran: (1) tematik pada tema lingkungan, (2) tematik pada tema hiburan,
(3) bahasa jawa, (4) matematika, (5) seni budaya dan keterampilan.

b. Kearifan Lokal dalam Kegiatan Ekstrakurikuler.

1) Seni Tari

Seni tari merupakan kearifan lokal yang paling awal diperkenalkan kepada siswa. Sejak kelas 1 siswa sudah diajarkan dasar-dasar tari. Mulai dari bentuk kaki, tangan, dan sikap badan saat menari, semua diajarkan secara bertahap (wawancara kepala sekolah dan ketua tim pengembang :16 oktober 2018).

Dalam proses pembelajarannya, siswa dipisahkan dalam empat kelompok yaitu kelompok putra kelas rendah, utrid kelas rendah, putra kelas tinggi, dan putrid kelas tinggi. Materi utama yang diajarkan adalah tari lepas yang terdapat dalam pertunjukan Reyog dan materi tambahan tari kreasi baru. Sebagai sarana aktualisasi, setiap tahunnya ekstrakurikuler seni tari SDN Kalimalangrutinmengikutipementasan bulan purnama di panggung utama aloon-aloon kabupaten Ponorogo.

2) Gamelan Reyog

Selain tari, SDN Kalimalang juga mengajarkan gamelan Reyog kepada siswanya. Pada wawancara pada tanggal 24 oktober 2018, ketua tim pengembang mengatakan bahwa gamelan Reyog berbeda dengan gamelan jawa slendro dan pelog. Instrumennya hanya terdiri dari kempul, gong, kendang batangan, dan selompret. Instrumen tersebut dimainkan tanpa adanya notasi tertulis, sehingga hanya mengandalkan musikalitas penabuh-nya.

Seni Gamelan Reyog diajarkan sejak siswa kelas 3 dan merupakan ekstrakurikuler pilihan dan terbuka bagi siswa putra maupun siswa utrid. Berdasarkan pengamatan peneliti pada tanggal 24 Oktober, ekstrakurikuler gamelan Reyog hanya diikuti oleh 
siswa putra. Sampai saat penelitian ini dilakukan, ada 20 orang siswa putra yang bergabung dengan ekstra kurikuler gamelan Reyog. Hasil dari latihan gamelan Reyog biasanya ditampilkan dalam pementasan Reyog di sekola maupun di acara Desa untuk mengiringi penampilan tari Reyog dari SDN Kalimalang.

3) Kerajinan Reyog

Sama seperti seni gamelan Reyog, kerajinan Reyog merupakan kearifan lokal yang diterapkan di SDN Kalimalang dan dikembangkan ke dalam kegiatan ekstrakurikuler. Kegiatan tersebut diperkenalkan pada siswa sejak kelas 3. Latihan kerajinan Reyog dilakukan 1x dalam satu minggu. Bentuk kerajinan yang diajarkan adalah membuat rapek, kace, boro, dan gombyok sampur. Hasil dari kegiatan tersebut digunakan oleh siswa dalam pementasan tari Reyog di Sekolah.

5. Dampak Pengembangan Sekolah Berbasis Kearifan Lokal terhadap Siswa SDN Kalimalang

Dampak pengembangan sekolah berbasis kearifan lokal di SDN Kalimalang dapat dirasakan setelah satu hingga dua tahun pelaksanaan. Pernyataan tersebut diberikan oleh kepala sekolah SDN Kalimalang pada sesi wawancara dengan peneliti. Guru pendamping ekstrakurikuler dan ketua tim pengembang, mengatakan bahwa pengembangan sekolah berbasis kearifan lokal membawa dampak positif yang signifikan terhadap minat belajar anak di sekolah, tingkat percaya diri, dan unggah-ungguh sopan santun.

Pernyataan tersebut sesuai dengan yang disampaikan oleh Agus Effendi dalam artikelnya. Menurut Agus, peserta didik lebih termotivasi karena dihadapkan pada hal baru yaitu nilai budaya sebagai sumber pembelajaran.

\section{KESIMPULAN}

Berdasarkan hasil penelitian dapat disimpulkan bahwa:

1. Kepala sekolah, ketua tim pengembang sekolah berbasis kearifan lokal, dan guru penanggungjawab ekstrakurikuler memahami dan memiliki pemahaman yang sama tentang sekolah berbasis kearifan lokal.

2. SDN Kalimalang mengimplementasikan kearifan lokal berupa seni tari, gamelan reyog, dan kerajinan reyog.

3. SDN Kalimalang melakukan 5 strategi pengembangan sekolah berbasis kearifan lokalyaitumembuatteam work, menyiapkan fasilitas penunjang, melakukan strategi pelaksanaan, melakukan kerjasama dengan pihak luar, dan menjalin kerjasama dengan masyarakat.

4. Bentuk implementasi sekolah berbasis kearifan lokal di SDN Kalimalang dapat dilihat dari pengintegrasian kearifan lokal dalam mata pelajaran dan kegiatan ekstrakurikuler.

5. Pengembangan sekolah berbasis kearifan lokal di SDN Kalimalang dapat memberikan dampak positif terhadap motivasi belajar siswa, tingkat percaya diri siswa, dan unggah-ungguh sopan santun siswa terhadap guru.

\section{DAFTAR PUSTAKA}

Agus, Effendi. (2011). Implementasi Kearifan Lingkungan dalam Budaya Masyarakat Adat Kampung Kuta sebagai Sumber Pembelajaran IPS. Edisi Khusus No. 2 Agustus 2011. ISSN 1412-565X

Eni. Puji A. (2013). Pengembangan Bahan Ajar Mata Kuliah Dasar-Dasar Desain Berbasis Kearifan Lokal Bagi Mahasiswa Pendidikan Seni Rupa. Jurnal Imaji. Vol 11, No. 2 Agustus 2013. ISSN 1693-0479.

Mujiasih dan Suprihantin. (2016). Pengembangan Pendidikan Berbasis Kearifan Lokal dan Hak-Hak Anak Di Sekolah Dasar. Yogyakarta: interlude.

Naela. Khusna. FS. (2018). Pembelajaran Berbasis Kearifan Lokal di Sekolah Dasar: 
156 imasi, Vol. 17, No. 2, Oktober 2019: 150 - 156

Sebuah Kerangka Konseptual.Inopendas Jurnal Ilmiah Kependidikan. Vol. 1 No.1 Februari 2018 Hal. 48-53. ISSN 26155443.

Pemerintah Republik Indonesia. (2003). Undang-Undang Republik Indonesia Nomor 20 Tahun 2003 tentang Sistem Pendidikan Nasional. Jakarta.
Wagiran. (2009). Pengembangan Model Pendidikan Kearifan Lokal di Sekolah Dasar dalam Menghadapi Masyarakat Ekonomi Asean (MEA). Jurnal Teori dan Praksis Pembelajaran IPS. Vol. 1 No. 1 April 2016. ISSN 2503-1201.

Zuhdan K. Prasetyo. (2013). Pembelajaran Sains Berbasis Kearifan Lokal. Prosidind, Seminar Nasional Fisika dan Pendidikan Fisika. Surakarta. FKIP UNS. 